The University of Maine

DigitalCommons@UMaine

Maine History Documents

Special Collections

1912

Applied Forestry: Written Particularly for Owners and Managers

James W. Sewall

Follow this and additional works at: https://digitalcommons.library.umaine.edu/mainehistory

Part of the History Commons

This Monograph is brought to you for free and open access by DigitalCommons@UMaine. It has been accepted for inclusion in Maine History Documents by an authorized administrator of DigitalCommons@UMaine. For more information, please contact um.library.technical.services@maine.edu. 


\section{RPPLIED FORESTRY}

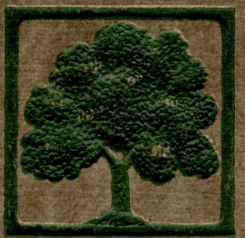


APPLIED FORESTRY 


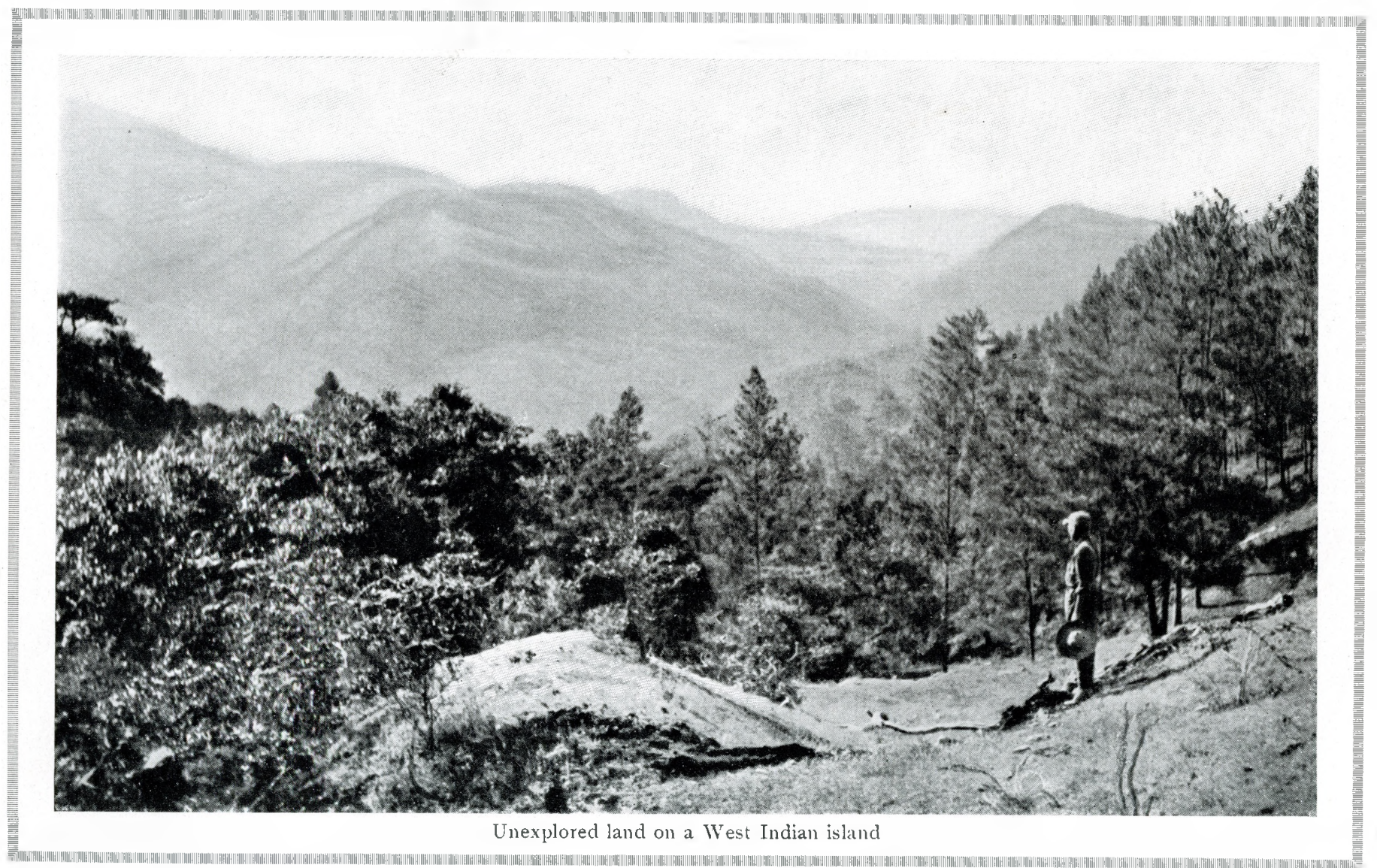




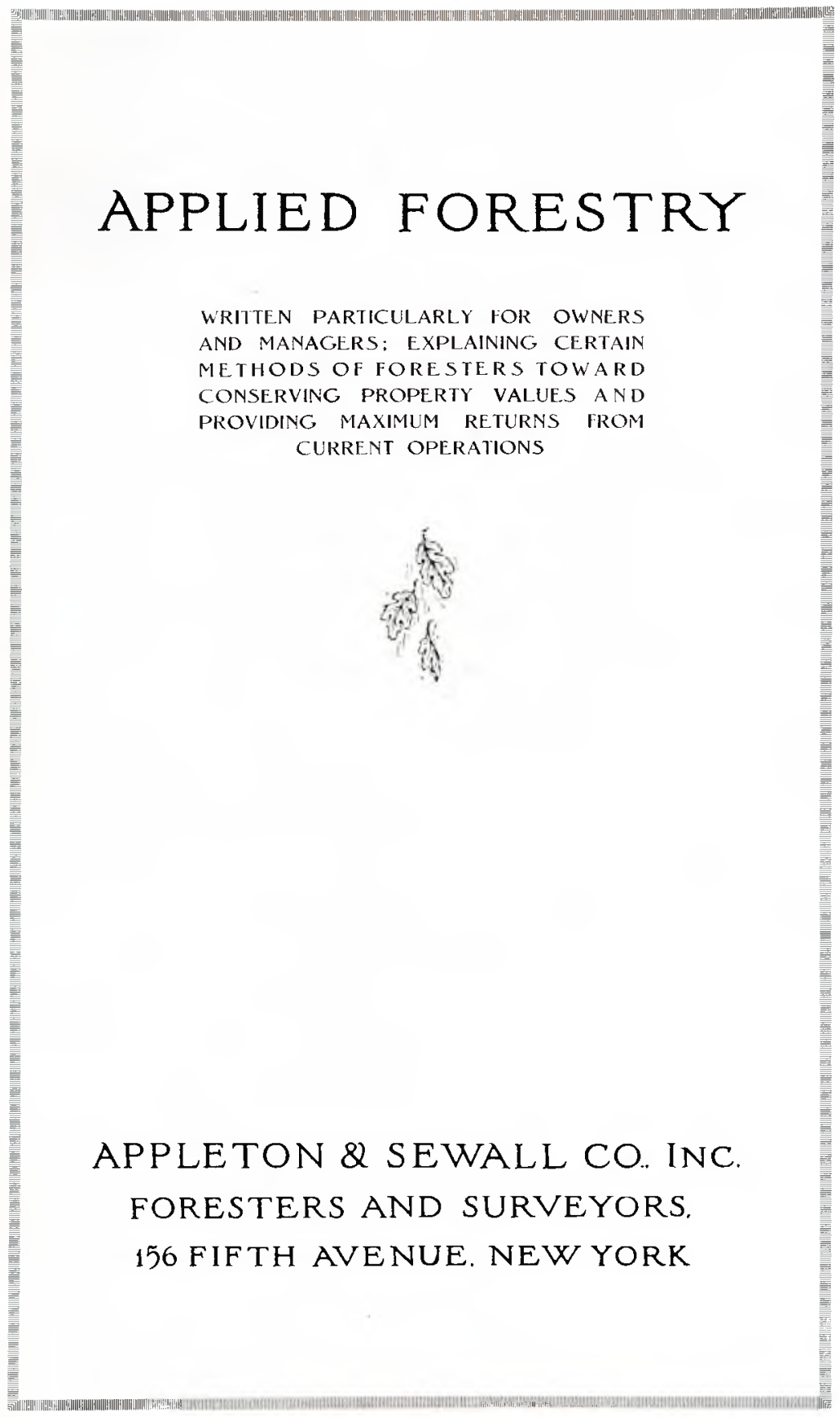


Copyriglst гог

By James W. Sewall

old Town, Maine 
T TOW much is a tract of forest worth? You can buy it for so much. But is it worth more or less than 1 that? You can sell it for so much. But are you get-
ting what it is really worth or will the buyer lose money on it? You can make it produce a certain amount of lumber. But could it be producing more, or are your operations depleting your principal without your knowledge?

The admitted fact that no owner of a forest can do more than make a guess as to the actual value of his property, unless its value is determined by scientific measurements, suggests the wide scope for the application of modern methods in the efficient management of forest properties.

An ignorance of basic worth at once betrays an ignorance as to the proper methods of conservation. The best of intentions, unwisely directed, may be doing more to lessen the value of property than careless waste for the sake of present profits. When scientifically taken, profits can often be greatly increased without harming the remaining values. In fact, as in all scientific management, scientific forestry works for the maximum returns for both present and future by avoiding needless waste and destruction and by making more intensive use of the present crop.

It is because of the deplorable ignorance of actual values, and of proper methods of protecting future values, that there has, within recent years, gone up a great cry as to the need of forest conservation.

So wasteful have been the methods, even under supposedly well regulated management, and so flagrant have been the abuses under the heedless management of those caring only for present profits, that a real danger has threatened the natural woodland resources of this country. The doleful picture of a country with a depleted and inadequate supply of wood material, held up before the eyes of the public to arouse sentiment against the fearful wastes going on in forest operations, is no

Wasteful methods 


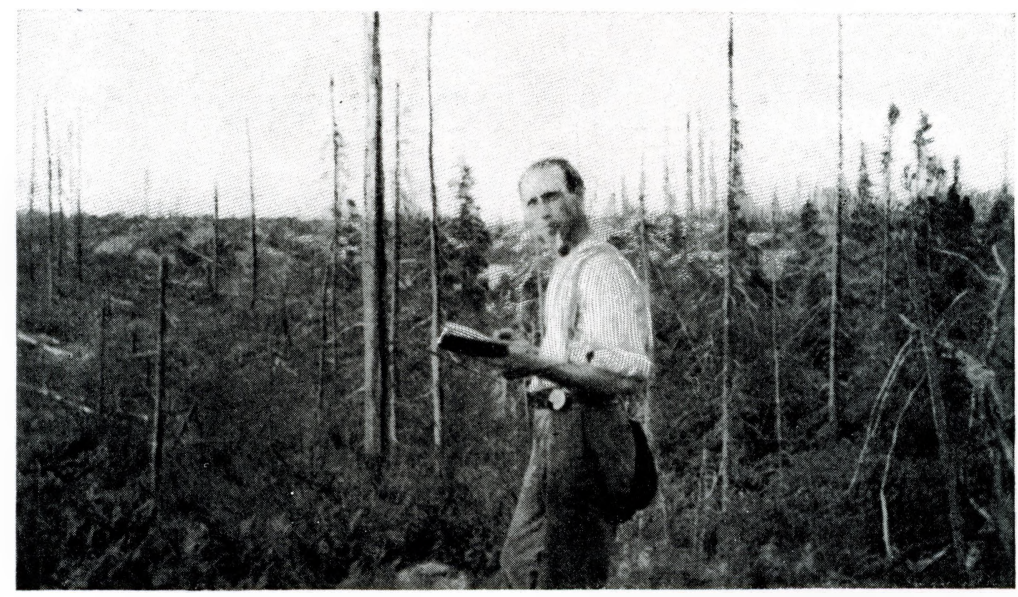

Eight-year old burnt land; the soil was cleaned off.

idle fancy. It needs only the application of figures to project the ratio of depletion into the future with a certainty of showing what a few generations or even a few decades would do toward the serious impairment of the practical supply.

What is true on a large scale as to the mismanagement of forest properties, is manifestly true on the smaller scale since the large is but the aggregate of the small.

In the matter of forest preservation America is far behind European nations in the adoption of sound policies. Even some of the Asiatic nations have exerted and are now exerting much labor in enhancing or at least up-keeping forest values, by methods which we in this country are only beginning to appreciate.

The forests of America are ample for our lumber demands - tremendous as they are - if the cutting is carried on with a proper regard for future growth. But it is a well known and admitted fact that the cut of many of our more valuable and sought after trees is greatly exceeding their growth. The certain rise in the values of such trees in the immediate future should of itself be sufficient to prevent owners from sacrificing for immediate profits trees that if allowed to grow would yield more later than the money possibly could if obtained now and invested in even the most profitable of enterprises. But it is non-appreciation of these facts rather than a willful 


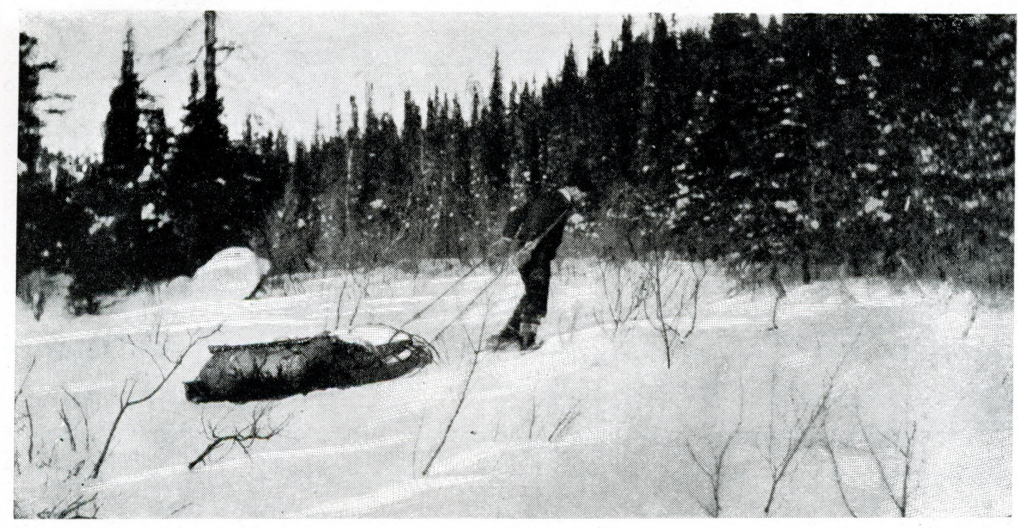

Winter transportation.

choosing of a short-sighted policy that affords the greatest danger to our resources for the future.

The steps now being taken in Europe and Asia for the preservation and extension of the forests have not been so much due to wise foresight as to actual necessity. In certain parts of those countries a condition has been reached which has more than fulfilled the warnings of cautious men of previous generations, and by methods of unscientific wood utilization even less wasteful than those which are being complained of in America today. It is the pressure of this situation, together with their more advanced and more intensified ideas of civilization, which have resulted in the efforts of the present and of the recent past to protect the forest properties of those countries from further depletion.

The principles of the efficient management of forest property can never be fully appreciated by considering only a limited area. It is only in the observation of the more conspicuous instances that one may understand the result of tendencies which otherwise might pass unnoticed.

An owner who knows only his own forest operations, and those only by guess work and second-hand information from others who reach their conclusions by guess work, often lacks the perspective which enables him to see his own opportunities for conservation in their true light.

It is for this reason that the study of forestry as a whole is a most important one either for the owner or for his advisers. The day has passed when guess work, either their own guess

A lesson from abroad

Value of wide study 
Four classes concerned

The land owner

work or that of their lieutenants, can satisfy the demands of progressive business men.

A brief outline of the principal ideas underlying forestry, and their application to efficient management of forest properties, is of value in moulding one's opinions, and turning them in the direction of obtaining maximum returns. But the actual use of those ideas as applied to any particular piece of woodland will vary greatly, so that much practical experience is needed to enable one to make the most of them.

There are, broadly speaking, four classes of people who are concerned with forests: the land owning class; the operators, who cut the standing growth; the mill men, who transform that growth from raw material to finished products; and the consumer. These classes at times may be interwoven,--one man may belong to all classes,- - but there are always found these main divisions.

The land owner, unless interested in cutting operations also, is chiefly concerned in his property from the standpoint of an

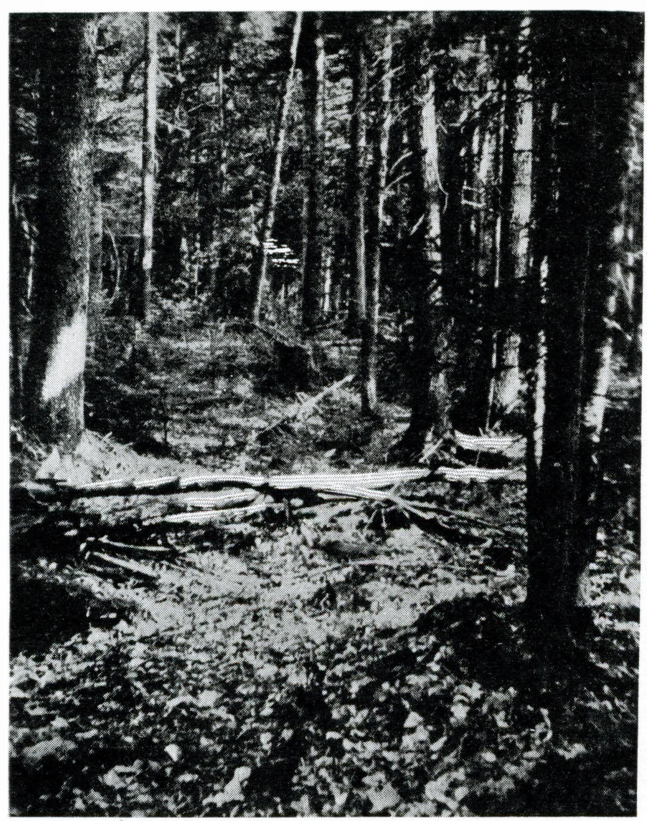

Thrifty spruce growth. Land like this should be a source of perpetual income. Note the vigorous reproduction. investment. He desires to know, first of all, whether or not his money, invested in forest properties, constitutes a safer, more profitable, and more desirable investment than if otherwise employed. This can be determined not alone from the present returns from his investment, but must take into consideration the future value of the property. If present returns are eating in to the principal unawares, and the property is losing in actual value 
so that a future sale would involve a depreciation which would swallow up present and intervening profits, then the investment value of his property is in question and must be given fundamental consideration.

If it is determined that the property constitutes a profitable and satisfactory investment the next problem which the owner must consider is whether or not he is getting the most out of his investment. It may be that a given piece of property, while profitable as a forest, could be cleared, and used for agricultural or other purposes, and thus yield a greater profit. If so, the forest must go, if maximum returns from the investment are desired.

Before a wise decision to clear a tract of forest and convert it into agricultural lands can be made, it is necessary to know whether the nature of the soil is such as will be most advantageous for field crops that could be handled at a profit in that locality, or whether it is such as might in time better support an artificially or naturally replanted forest.

In some cases the investment of the capital necessary to obtain maximum results in the long run is not possible to the present owner, and he must either sacrifice his forest, or hold it with the practical certainty of depreciation unless it is properly property preserved. Under the pressure of lack of capital, a sale is sometimes made at a low figure, based on present conditions, while the opportunity of preservation and enhancing the value through wise management, being unknown, is not figured as an asset, and the owner loses heavily through lack of knowing what his property is really worth. If he knew its prospective value, as well as its present value, he could often sell at a premium what he otherwise would give away.

In buying property, however, the conditions are reversed, and the buyer may easily make a false estimate of the prospective value of a forest, and so fail to realize on the property at the price he has paid for it. The buyer may also, through lack of knowledge, think a price is too high, and fail to take advantage of what, if he did but know it, would have proved a real opportunity.

The methods of arriving at forest values, prior to the advent of scientific methods of measuring, charting, surveying, tabulating, mapping, and figuring, were not such as to commend themselves to the good judgment of the modern business man 


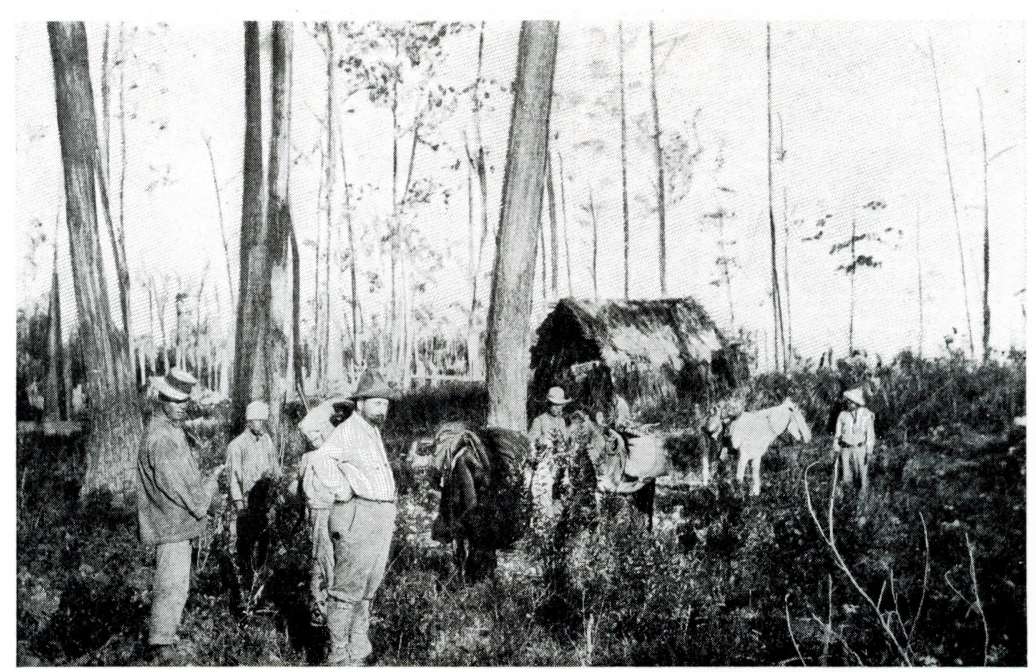

A Southern party. We cover all sections of the American continent.

who knows that exactness is often the difference between failure and success.

Guessing at values obsolete

Not so very long ago, and even yet in many instances, the value of forest property was appraised by sheer guess work. The cruiser goes through the forest, notes a number of the trees, or sometimes even observes them from a mountain tree top, and after all his jottings and data are considered, in what must be a rather superficial manner compared with scientific methods, he judges value. In their particular locality, where they have had long continued opportunity of seeing lumber cut and what it will turn out, a surprising degree of accuracy is often shown by these cruisers. But the personal equation is always present, and while there are many instances where land has cut just about what the cruiser reckoned, there are also many instances where a great variation from the true valuation of the property has been found. Compared with the scientific methods of the forester the ordinary cruiser's work is refined guess work, sometimes accurate in its results, and sometimes wild to the point of absurdity.

A better understanding of the difference between the two methods of determining values can be gained by simple comparisons. There are men who can guess the weight of a person so closely that it tallies favorably with the scales in a majority 
of cases. But back of them are thousands of experiences for comparison, and immediate and actual knowledge as to how nearly correct their guesses are. It is all right for amusement to guess at weights, but no one would think of buying meat or sugar that way. No butcher would buy his beef by even his own guess at the weight, and yet his experience in sizing up the weight of a piece of beef is often a matter of daily recurrence.

The land owner must therefore deal with the question of obtaining a knowledge of forest values, and must base all his operations upon those determined values, in paying taxes, in buying, selling, improving, or converting the land. The degree of error in the original valuation cannot be made up by any amount of wise management, and must appear in the result. Sometimes, fortunately, the error is on the side of conservatism, and the owner profits more largely than he was led to expect. But sometimes the error is in the other direction, and what might have been a profitable move turns out an inexpedient one.

In borrowing money on Timber-Bonds accurate estimates of the value of the property, based on actual measurements by competent men, are necessary to prevent mistakes on the part of the seller, underwriter, or investor.

Whether operators are wasteful or conservative and economical depends largely on their point of view. There are some operators whose policy it is to go over the land once and clean it up thoroughly, take all the profit there is in it, rather than to cut out a few selected trees and let the rest grow for future operations.

Another class of operators, particularly those for large companies, are more inclined to look forward, and are more and more becoming saving agents for the forests. They realize that they, as a class, are perhaps in a position to do more than almost anyone else for the conservation of our woodlands. Theirs is a work that calls for a high type of administrative ability and leadership, and it is only natural that such qualities should go hand in hand with a proper consideration of the future values of the property. There are many broad-minded operators who, so far as their financial needs will allow, are carrying on a correct operation of lumbering, according to the best methods which the science of forestry can devise.

Between these two extremes in the types of operators are many whose intentions are to conserve the property and get

Policies of operators 


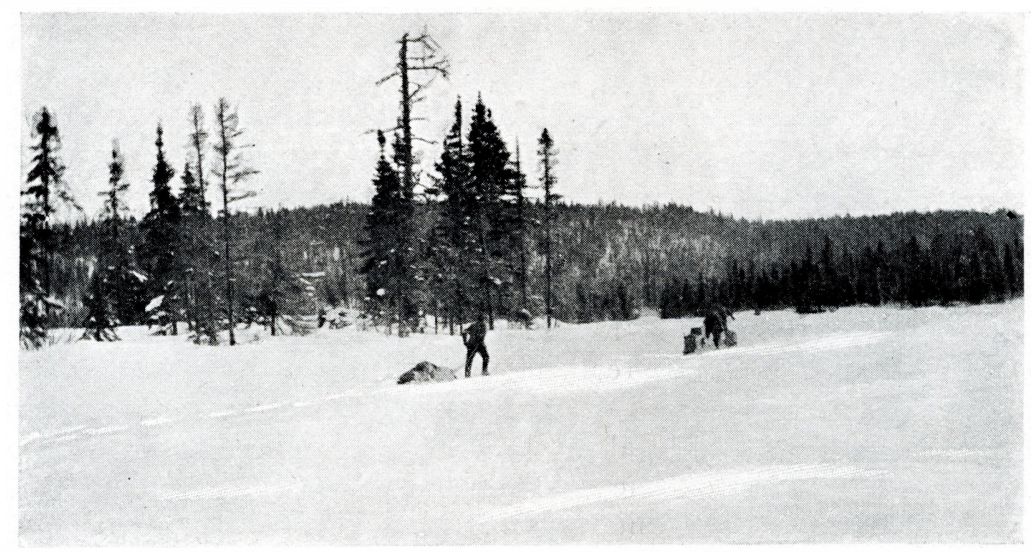

Moving camp in the North. It takes practical woodsmen to meet such conditions as these.

the maximum profits out of their operations, and yet who fall short in both instances through lack of knowledge of what truly constitutes efficiency.

Two kinds of mills

Mill men are of two very distinct classes. One has a light investment of capital, and desires returns of a comparatively high profit, and is not dependent on a restricted territory for any great length of time. The other class has heavy investments of capital, and expects sure but lower profits, and is dependent on a restricted territory for a long term of years.

The portable mill, jumping from place to place, and skinning the woods clean, is the best illustration of the first mentioned class. The enormously expensive pulp mill, with its network of water storage basins, sluices, heavy machinery, and other permanent features, is a type of the second class.

While outside connections and influences sway the individuals of these two classes, it is generally conceded that the first named class is a forest destroyer, and must tend to be so by the financial exigencies of his means and calling. The other class has often a profitable opportunity to be a forest conservator, since he must consider the forest as much a part of his plant as his machinery, and whatever prolongs the value of the forests increases the value of his investment.

The The consumer is interested in the conservation of the forests consumer's viewpoint both as a citizen of the nation, with a care for the future, and as a user of lumber and the products of the forest, since whatever 
is wasteful in lumber operations must eventually come out of him. The ideal of scientific forestry is to provide for the consumer the maximum of material for the minimum of expense, even while it provides a maximum of present and future profit for the land owner and forest operator.

Lumbering is the actual instrument by which profits are derived from forest land, and it is upon the way this instrument is used, and with what foresight and economy and common sense, that the present and future value of forest lands depends.

In the past lumbering has considered the forest as a single crop to be harvested once for all, rather than as a continuous crop. Under the economic conditions which have prevailed that was, unquestionably, the most profitable method for the operators. Men work in the woods to make money, and so long as apparently unlimited resources are at hand few will stop to consider a remote and improbable future, when there is a keen need and opportunity for immediate profits. The working idea has been, as a rule, to get out all available timber as cheaply as possible, considering neither the larger trees carelessly left, the young growth harmed, nor the condition of the forest when the work is completed. Conditions have seemed to call for this, and in some places still do. But under many present circumstances it is both wrong and wasteful.

Upon the idea of getting out lumber as cheaply as possible, as the only prime motive, there has gradually been grafted a kindred idea of saving for a future cut. From economy in the mill has come economy in the woods. The first step has almost always been the enforcement of a specific diameter limit, below which no trees shall be taken, and that limit has saved many areas to forest land that otherwise would have been depleted.

The head woodsman for a large land owning company pointed with pride to a distinctly marked line of growth which was visible from the lake. On one side of the line were the light tops of hard woods, on the other were black masses and clusters of spruce spotting the hardwood background. "That's the way with all our towns," said the woodsman. In that locality a specific diameter limit has been enforced for soft woods, with the penalty of increased stumpage price on undersized trees, and the result has been the careful sparing of young trees of the more valuable kind. 


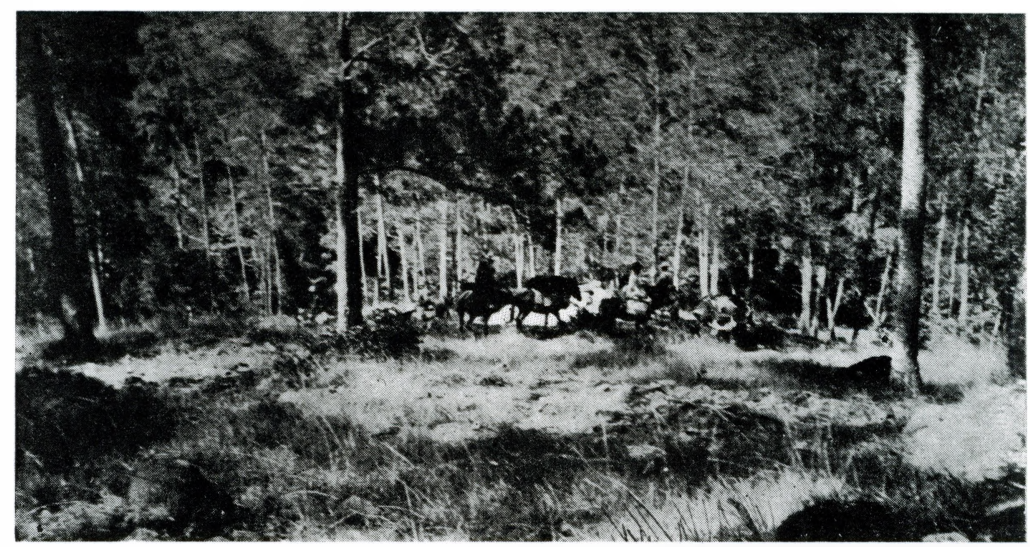

Moving camp in the South. It requires experience to cope with the widely varied conditions we are called upon to meet.

With the diameter limit idea came also the rules for economy in cutting: low stumps, small tops, sparing of the smaller individuals of valuable species when making bridges, skidways and camps; careful scaling, clean picking up on penalty of payment for cut lumber left. Even without technical aid there has been this tendency among thoughtful owners and operators to develop and conserve the forests along lines in which scientific forestry effects its greatest results.

Until a few years ago lumbering was almost the only large semi-engineering industry into which the services of specially trained and educated men had not been called.

Science now entering the woods

Now, the application of science to lumbering is being worked out, and under systematic management the forest is being cut with the idea of both continuing and improving the tree holdings operated upon. Specially trained men give exact advice on handling, and that advice is being followed with profit. The engineer is aiding the lumberman just as he aids the miner. Under his guidance an exact science of lumbering may be discerned as a future possibility. Such lumbering will get the greatest real profit from each piece of land. Land that is unfit for agriculture will be kept under timber, and the wood crops on such lands will be harvested at proper intervals and in the proper way. Land that is particularly fit for agriculture will be cleared and devoted to it, and in this way the country will approach maximum production, a condition which today is only a dream of the future. 
Forestry as a science is new in America, and like all new professions has proceeded from theory to practice, and mistakes have been made in the effort to fit the theory to the practice. Men with proper technical training, but without experience, have come in contact with practical woodsmen, and have been literally laughed out of the woods for recommendations which even a little experience would have prevented them from making. One young forester strongly objected to a main hauling road following the valley of a stream where there was much softwood growth. He advised shifting it to the ridge top. His technical education told him to save the young growth of the more valuable species, but common sense and experience were wanting or he would have known that it was not profitable to yard logs up hill, and that heights of land are not good places for main roads!

In the efforts of such men to get their bearings, and modify their theoretical training with the wisdom of practical experience, much harm has been done by creating in the minds of practical men the idea that technical training hits wide of the mark. There has perhaps been more pleasure in circulating anecdotes to illustrate the mistakes of the newcomers than in telling how technical knowledge was able to teach old dogs new tricks. Human nature is not different in this respect than in all other departments of life where innovations of any kind are met with misunderstanding and consequent opposition. But science has triumphed too frequently over the prejudices of human nature to be retarded in its advance by a few mistakes and the misunderstanding of their import.

Although forestry is as yet but a new profession in America, and the first generation of trained foresters is still young, these men are quickly absorbing the wisdom of experience and mixing it with their technical knowledge, and are demonstrating the definite commercial value of the science of the woods.

The future of forestry as a profession is a matter of which no one can speak with assurance, and yet it is but reasonable to say that greater and greater reliance must continue to be placed on more scientific methods, and that efficient administration of forests must naturally take the place of guess work and rule of thumb methods, and that the present wasteful tendencies will eventually be turned to practical and scientific conservation.

In years to come
Technical men misunderstood 
It is a far cry from the explorer of fifty years ago measuring his lumber visually from a mountain tree top to the trained man of the present day measuring individual trees with calipers. The change which has brought about this contrast in measuring forest values has brought many new standards and methods, and will continue to evolve towards the maximum of intelligent effort in forestry.

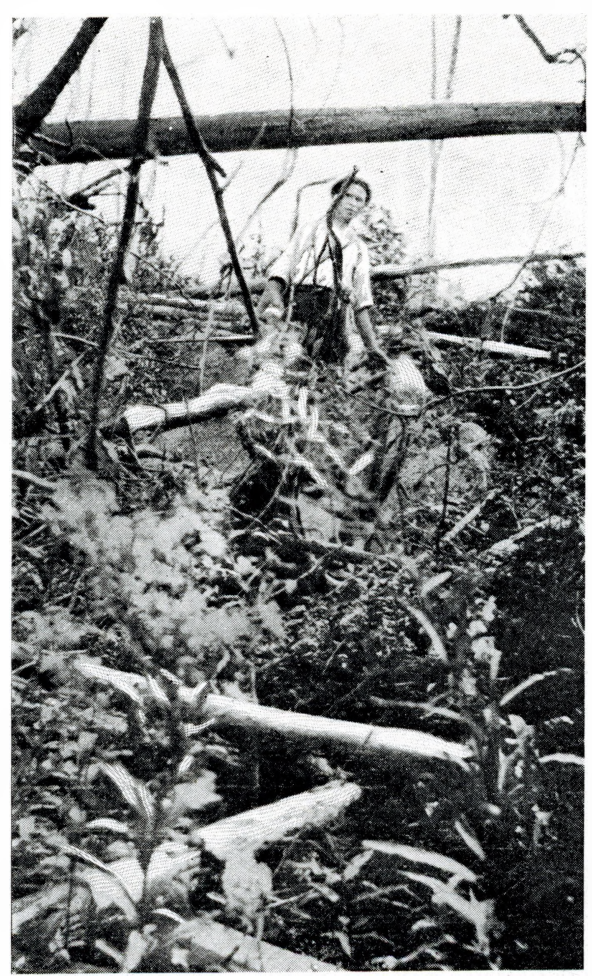

Heavy Burn in Northern Forest. 


\section{OUR FORESTRY SERVICE EXPLAINED}

The owner of forest property, desiring to obtain definite knowledge of his forest values, and to know if his operations are in line with conservation both for himself and the nation, will wish to know something of the services he may be able to obtain from experienced foresters.

The operator or the mill man will also desire to know how to arrive at an accurate knowledge of the forest values of a given territory.

To such we offer our services as foresters. Our wide experience in forestry work, together with the obviously logical methods of our procedure, will commend themselves to the judgment of men experienced in the broader aspects of business, appreciating the value of technical knowledge, but being obliged to depend upon others for its application.

Our service is as varied as the needs of the problem to be considered, and but a general idea of these methods can be given, leaving it to the individual owner or operator to see what portion thereof can be applied with profit to his own business.

The consideration of a typical case will serve to illustrate.

There is a tract of wild land, about which little is known. It was surveyed and the outer lines run forty or fifty years ago, and it has been cut on more or less ever since. An examination of it had been made by several local cruisers, and rough plans turned in.

It is desired to know something definite about this property. There may be an offer from a prospective buyer, or the owners may desire to $\log$ it in such a manner that the lumber will last and bring in a continuous income. Parts of it may be burnt and it is desired to know how much. We may think the taxes are too high. Perhaps it is desired to borrow money on the timber value, and erect a mill to get the profit that has hitherto gone to others. Or a buyer may wish to know what he is getting, or what price to pay in order to receive proper interest on his capital.

Such are some of the conditions which usually call for our services. After agreeing on general ideas, the procedure is as follows, according to the work necessary to be done: 


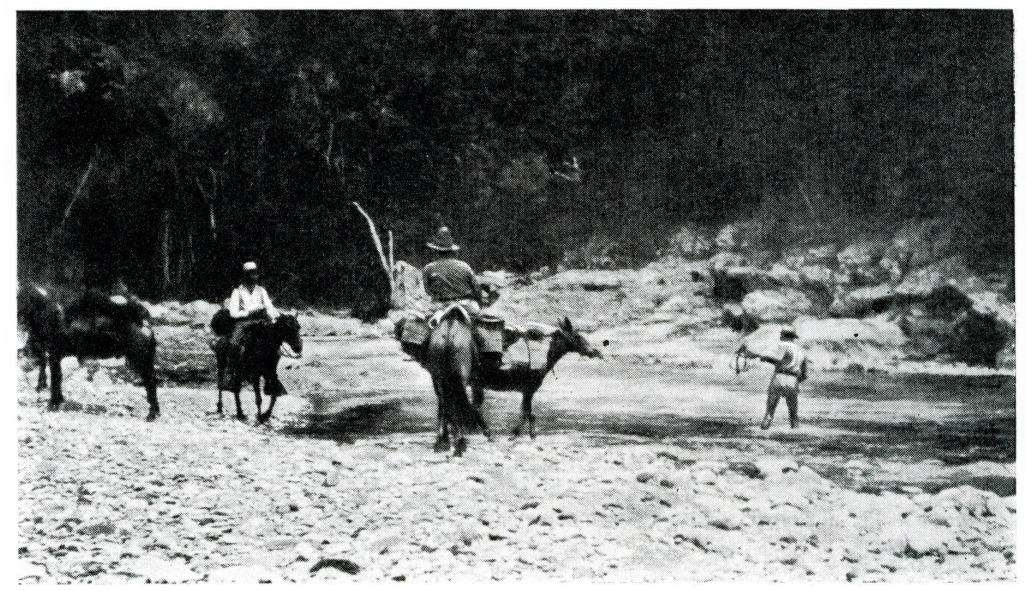

Fording in the South.

If the land requires surveying we first do that. Records and data of the original survey will be obtained, and the old indistinct lines plainly marked on the ground. Lost corners will be found or relocated, and properly set. Careful measurements will be made to ascertain the true acreage, and posts set or trees marked at intervals, usually every quarter mile or half mile, for future reference. Lines of sub-division, according to the wishes of the owner, will be run through the tract, blocking it up into small units of area, as for example the square mile. These lines also will be well and accurately made and marked.

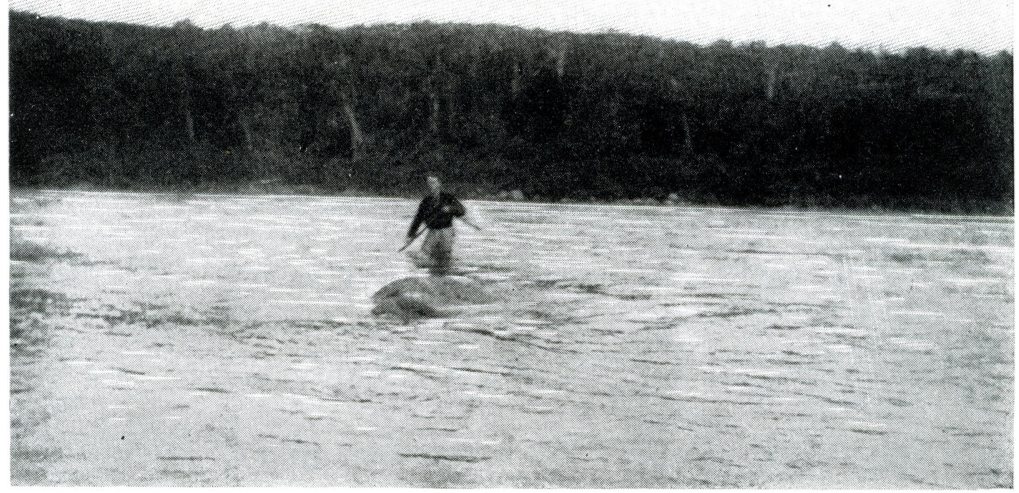

Wading in the North. 


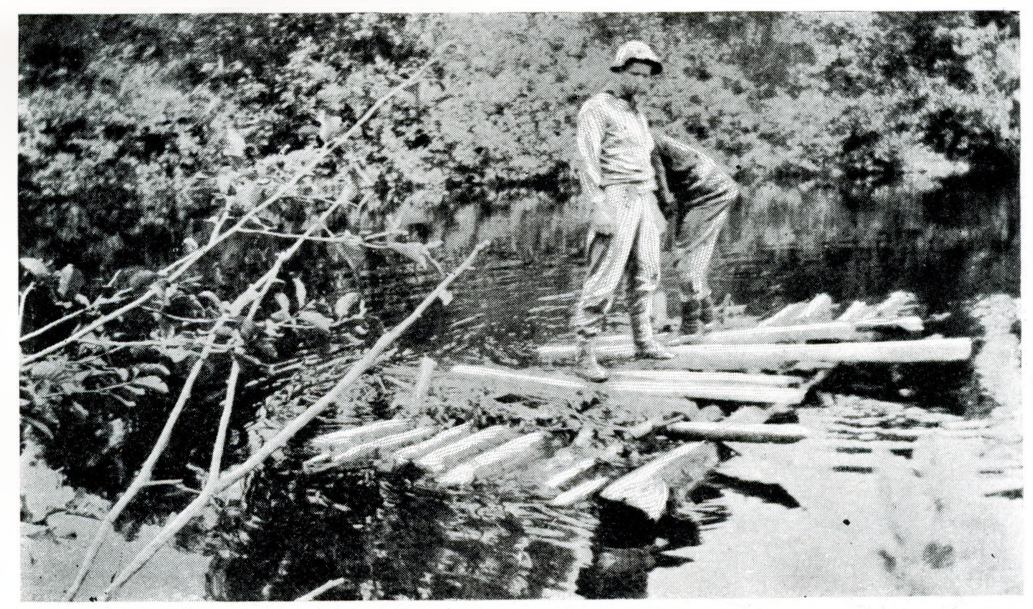

No nails or rope in this raft.

The instruments used in wood surveying are usually the magnetic compass and the Gunter's chain. Transit lines are sometimes run, and the solar compass is sometimes employed, but the element of cost must be considered, and the ordinary compass is recommended as being accurate enough for all practical purposes. An error of one rod to a mile, $1: 320$, is considered allowable in forest surveys. The compass is the only instrument with which lines can be run in the woods at a reasonable rate.

The usual method of marking lines is by well defined blazes on the trees which the line intersects, and of quarter-spot blazes on trees standing near the line. Posts set at the corners are surrounded with stones, when practicable, and witnessed by trees being blazed down about them.

The posts are properly marked for the corner with the timber scribe or marking iron, and both posts and witness trees bear the date and the surveyor's mark. Where lines cross important roads and waters, the usual method is to plainly indicate them by witnessings or posts so that they may readily be picked up.

A stadia attachment to the compass is a convenient chain supplement, avoiding the necessity of triangulation of inaccessible distances, such as water or gorges.

The cost of well made compass lines in ordinary country varies between $\$ \mathbf{1 2}$ and $\$ 25$ per mile. Such lines need not be renewed for a period of twenty to twenty-five years. 
As an adjunct to surveying, dependent on the desired degree of accuracy, and the desired results called for, instrumental traverses are made of the principal waters and roads on the tract. The transit, with stadia attachment, is the instrument most generally employed on this part of the work. The cost approximates $\$ 6$ per mile.

The After the necessary surveys are made, and in actual work, exploration while they are in progress, exploring parties gridiron the tract at stated intervals, usually from one-sixteenth to one-half mile apart. These parties keep exact records of all the natural and artificial features they meet with-roads, streams, heights of land, growth, conditions of growth, burns, bogs, etc. These are all located on their lines of travel.

If a topographical plan of the tract is desired, and such a plan is usually to be recommended except in very flat country,

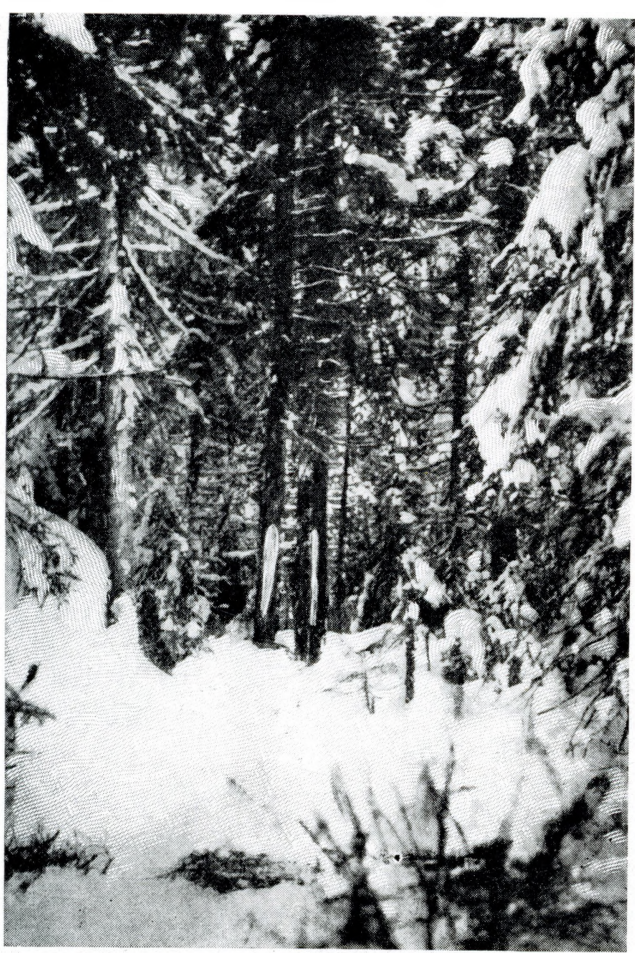

Spotted line in a Canadian forest. Note the heary, well-defined spots. aneroid barometers are carried by these explorers, and read at numerous intervals. From this barometric work elevations of various points are obtained, and a rough contour system can be drawn.

As the exploration party travels it also takes a record of the diameters and kinds of trees, by measuring with calipers those on specified areas. For instance, a strip 66 feet wide is measured right along the line of progress; or measured acres, halfacres, or quarter-acres are taken at regular intervals along the party route. Where 
timber is very valuable this method may be varied to an actual count of every tree. Usually in such latter instances the subdivisions are smaller than the square mile, the forty acre tract being perhaps the standard. As in any other expenditure for knowledge the degree of expense must vary with the value of the principal about which information is sought, and the higher the intrinsic value of that principal the more refined can be the methods of determining facts about it.

These results are tabulated on specially prepared sheets. Calipering work is done in order to obtain a sample acre of tree facts for the tract or one of its subdivisions.

There are many ways of doing this field work. One way which has been found especially satisfactory in fairly dense growth is to measure the trees in quarter-acre circles, a radius of 59 feet. An assistant does the calipering, runs out the tape to check distance, and sometimes tallies the diameters called off. But each tract of land will call for certain methods, and no general rule can be laid down as to what the best method may be. The method chosen is influenced, not only by the land itself, but by the results that are desired, the need of quick work, and other incidental things. But accurate measurements must be insisted upon in all methods used if the work is to be correct.

The information obtained by the survey and the exploration usually covers the following points:

Tract lines are marked on the ground and tract areas are known.

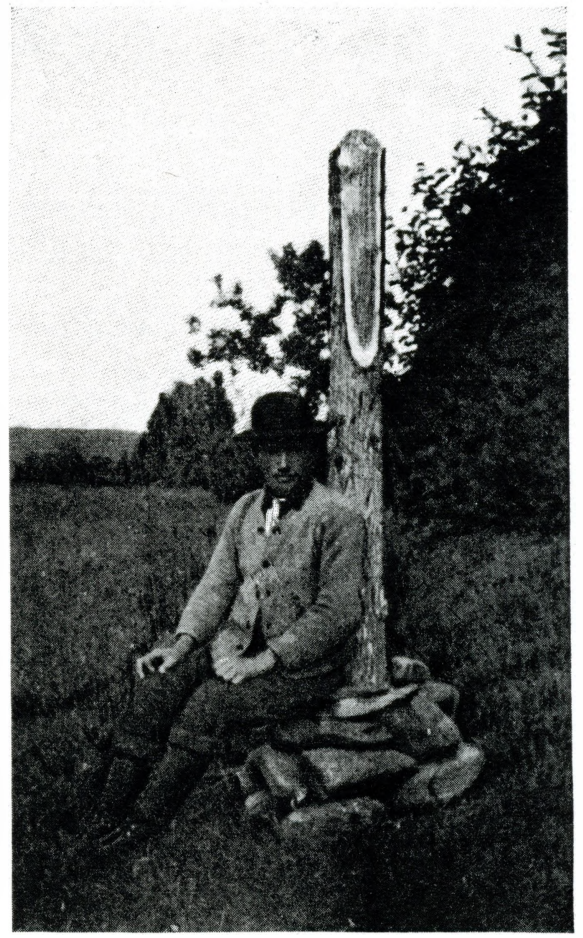

The bark woujd not strip from this dry cedar post.
Methods of field work 


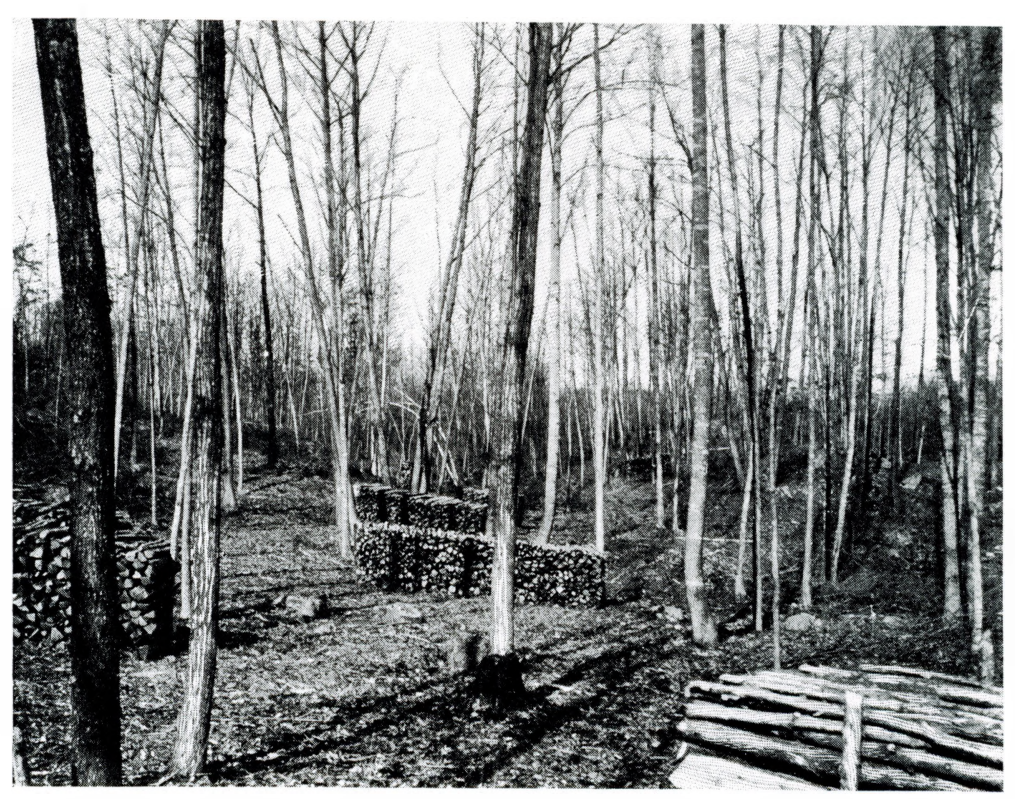

A heavy improvement cutting

Record of interior details for mapping is had.

Trees, the kind, diameter, and number per acre.

The slope of the land.

The rock and soil characteristics.

The species reproducing.

The quality and condition of the growth.

The merchantable condition of the tree-crop.

Logging chances and conditions.

Any damage caused by fire or other extrinsic happenings.

The data so obtained are tabulated on special forms. Tables are prepared showing the size in board feet or cords of the individual trees, and by applying these tables to the recorded acres, a sample acre of quantity in feet or cords is obtained. This sample acre multiplied by the whole number of forested acres under consideration will give the total amount of lumber on the tract, proper discounts being made for faults.

A sample

From the tabulation of the data the report is worked up. report An outline of an ordinary report follows. In actual practice of course this outline is modified by omission or increase of detail according to the nature of the tract, but this serves to show the basis for a usual procedure. 


\section{REPORT}

Name of Tract.

Forest area in acres.

Waste area in acres. I. Water.

2. Burn.

3. Bog, etc.

Total area.

Total Estimates and Valuation.

Species.

Board feet or cords. Value per M or cord. Total Timber Value. $\$$

Value per acre for timber

Land value per acre, stripped of timber

$\$$

Total value per acre

$\$$

Value of tract $\$$

\section{THE TRACT}

(1) Owners, with fractions (if any) and addresses.

(2) General location

Reference to (a) topographical plan.

(b) timber plan.

(c) field notes of survey.

(3) General topography and elevation.

(a) Water systems.

(I) Outlets.

(2) Relation to each other.

(3) Relation to present or proposed railroads.

(b) Elevations; extremes and aver-

(c) Slopes; steepness, regularity, etc.

(4) Geological features (a) rock.

(b) sub soil.

(c) soil. 
(a) Temperature; Yearly and monthly extremes and means.

(5) Climate (I) Length of growing season.

(b) Precipitation; Yearly and monthly means and influence on forest growth, stream flow, etc.

(6) Transportation (a) Drivable waters.

(b) Railways.

(c) Roads.

(d) Cable ways, flumes, tramways, etc.

(7) Market (a) Mills: present location, kind, capacity and efficiency.

\section{THE FOREST}

(I) The species

(a) Names and characteristics.

(b) Range and altitudinal limits.

(c) Tolerance, moisture requirements, soil requirements.

(d) General size, quality and thrift in different situations.

(2) Forest Types (a) Percent of each species in each type.

(b) Where found and characteristics.

(I) Elevation, soil and moisture.

(c) Relative predominance and value in the forest.

(3) Present forest (a) Thrift.

conditions. (b) Quality.

(c) Tolerance.

(d) Prediction of yield.

(e) Argument for and against different systems of management, such as clean cuttings, thinnings, plantings, etc.

(f) Damage and its prevention.

(4) Merchantable condition. (a) Size and for what used.

(b) Quality.

(5) Estimates. (a) Species.

(b) Diameter or sizes taken. 
(6) Lumbering. (a) Logs, pulp, etc.

(b) Cost on landing.

(c) Length and cost of drive or haul.

(d) Present waste in lumbering and methods of elimination.

(e) Suggested improvements in present cutting and transportation.

(7) General operation or "working" plan.

\section{SUBDIVISION REPORTS}

Forest area.

Waste area (I) Water.

(2) Burn.

(3) Bog, etc.

Total areat.

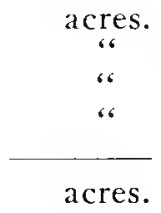

Estimates

Species.

Board feet or cords.

Topography. (1) Valleys and heights.

(2) Drivable streams or railways.

Soils.

(I) Forest and agricultural land.

(2) Quality and types of soil.

Growth. (I) Present types.

(a) Occurrence.

(b) Condition.

(c) Damage.

Lumbering. (I) Footing for horses.

(2) Swamping and yarding conditions.

(3) Length of haul.

(4) Camp locations.

(5) Avoidable waste.

Details of working plan and definite recommendations.

(I) When, how and where to operate. 
Would not such a report be valuable to you in the general handling of your lands, or in the buying, selling or borrowing of money thereon?

In scientific handling of forest properties it is possible to go still further. By analyzing carefully the different trees there may be determined the yield which may be cut from the forest at stated periods without depletion of principal.

This knowledge is of especial value to land owners and to mills owning their own timber lands. For lack of this knowledge in the past many serious mistakes have been made and losses

Future

yield

determined incurred. By cutting more frequently or more thoroughly than the increase would permit some lands have become seriously depleted without the owner's knowledge until it was too

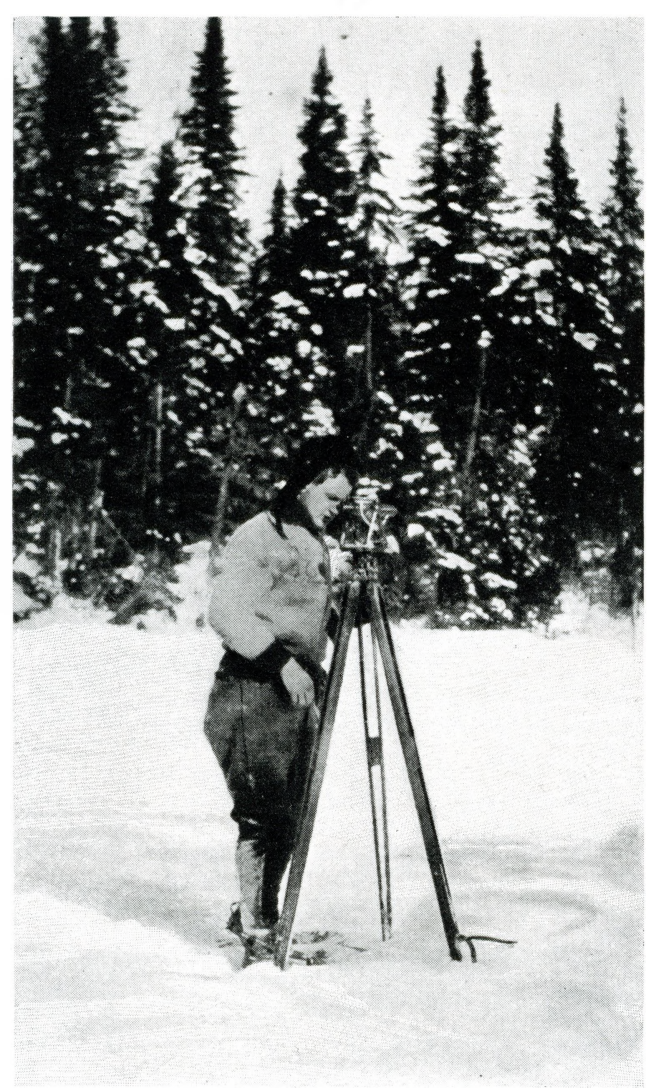

Light mountain transit used for traverse work. late to save them.

One method of arriving at a knowledge of future yields, in a forest containing many ages of growth, is as follows:

Sample acres are measured throughout the tract, and the trees within these acres measured as in obtaining a present estimate. This work may be done in the same manner as in estimating, but smaller diameters will be taken into account than if the estimate is being made for present growth only. Even the seedlings will be counted on a few acres. A record will also be 


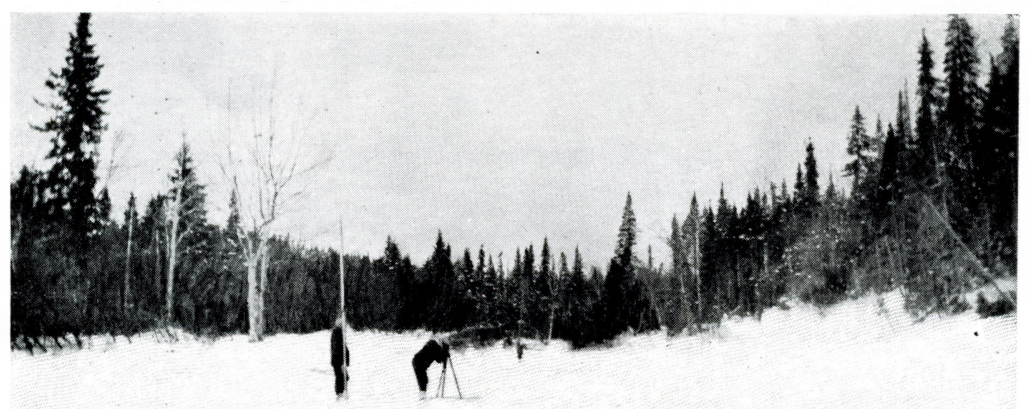

Running levels to control barometric work.

kept of what trees will probably die out through crowding and shading.

As large a number of felled trees of different diameters as practicable are measured. If logging is going on this can be done in the works. Besides the diameter at breast height, the measurement of growth at breast height or on the stump is made by counting rings back for ten years more or less. Different types of trees are classified by height as well as diameter. This adds to the accuracy of the figures but is not always necessary. The best and cheapest way can be decided on the ground by the forester.

The rate of height growth is also determined, and the volume of the trees at different ages is computed. This is often a long and somewhat expensive process, but for practical purposes it is possible to shorten it greatly by certain slurring methods which give the desired results for local areas.

From the volume so obtained for trees of different diameters and growth between different ages, the future growth and yield can be predicted.

The forest owner may fix the most profitable size at which to cut, and may know the yields of merchantable lumber at future dates after such cutting. He can definitely plan what his forest is going to be worth, as well as what it is worth, and can figure whether he will get good interest on his money if it is left invested in certain tracts of land. 
Especially in estimating fire damage to young growth is this acquisition of data valuable, allowing future as well as present loss to be accounted for.

When Planting is as yet impracticable in most wooded territories planting is profitable but the day is fast approaching when it will become profitable. Even today there are many areas that would pay to plant. On vast wastes left by fire and by devastating logging planting can be carried on with profit by the State or by corporations, especially where large mills expect a permanent supply of timber from given areas. Here and there are cases where individuals should artificially restock their holdings.

In planting it is the work of the forester to know what species is best adapted to the soil, climate, and market. He knows how trees affect each other, and how soil, climate and species are inter-related. He will not plant a tree calling for rich soil in land that has poor soil. He will not plant a tree of a valuable species in mixture with one less valuable but stronger

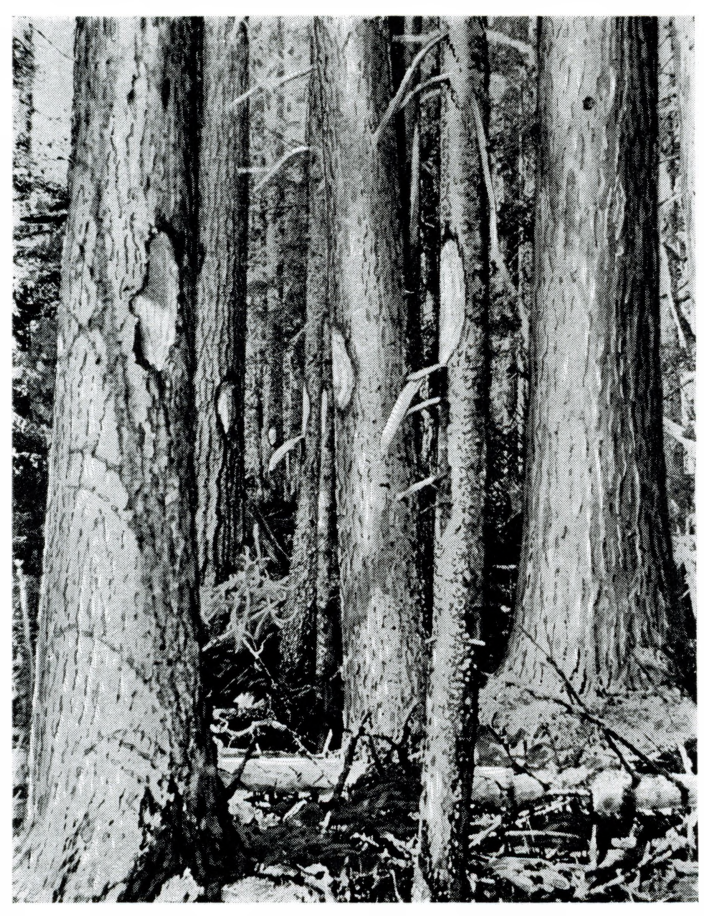

A spotted line through old growth. which will crowd out, over-shade and kill its better neighbor. He knows that preliminary studies, even elaborate ones, are often the cheapest in the end. It will pay the owner to be sure he is planting the correct species in the right way, and this cannot always be readily d e t e r mined without careful examination.

The management of lands is greatly simplified by applied forestry. The facts 


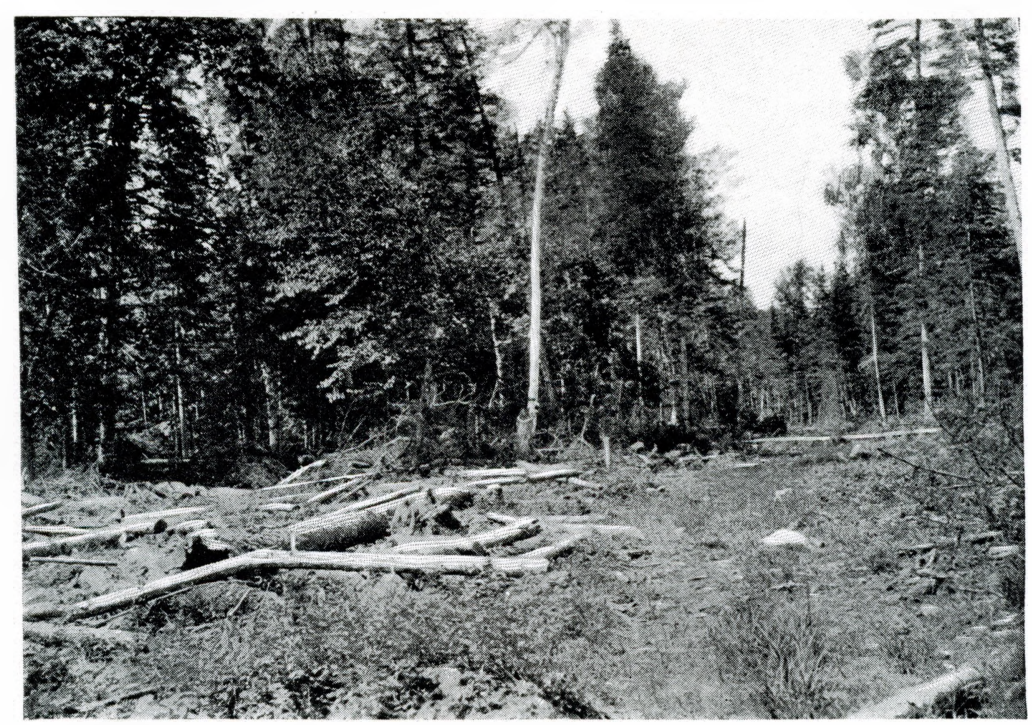

Efficient management avoids this kind of waste.

once definitely known afford a basis for all future decisions, and make unnecessary the continual consideration and reconsideration of the essentials involved. The owner or manager has at his command accurate plans showing growth and topography; a report giving present and perhaps future yields in timber; and definite plans for efficient handling. He also has complete survey records by which his acreage is known, and on which he can execute definite deeds in case of partial or total sale. Moreover, his land is marked to correspond with his records.

Proper management, however, is an elastic term. It varies from year to year, and with each locality. What was proper management fifty years ago is not proper management today.

But the manager who lives up to the name makes it his business to know all that is necessary to be known about his property. How he will get his knowledge will vary with difThe efficient forest manager ferent men and conditions. On a small tract of land with limited business he may often obtain his knowledge at first hand. He will tramp through the woods himself, decide on his plans for cutting, do his own timber estimating, mapping and surveying. But this is possible only on a small tract 
and with a manager who is not only capable of doing it, but who has plenty of time at his disposal.

In ordinary practice, especially in larger tracts of forest property, the manager is obliged to get his knowledge at second hand. The accuracy of that knowledge will largely determine the efficiency of his management, since no amount of wise management will rectify mistakes in the plans upon which operations are based.

If the manager is one who works toward the higher standards of his calling he will desire accurate knowledge, and he will employ surveyors and explorers to define his boundaries, estimate

When manage-

ment changes

his timber, and recommend scientific ways of handling. He will require them to provide him with intelligible and permanent records, which can be understood by other minds than his own. The records which are held in the heads of a few woodsmen will

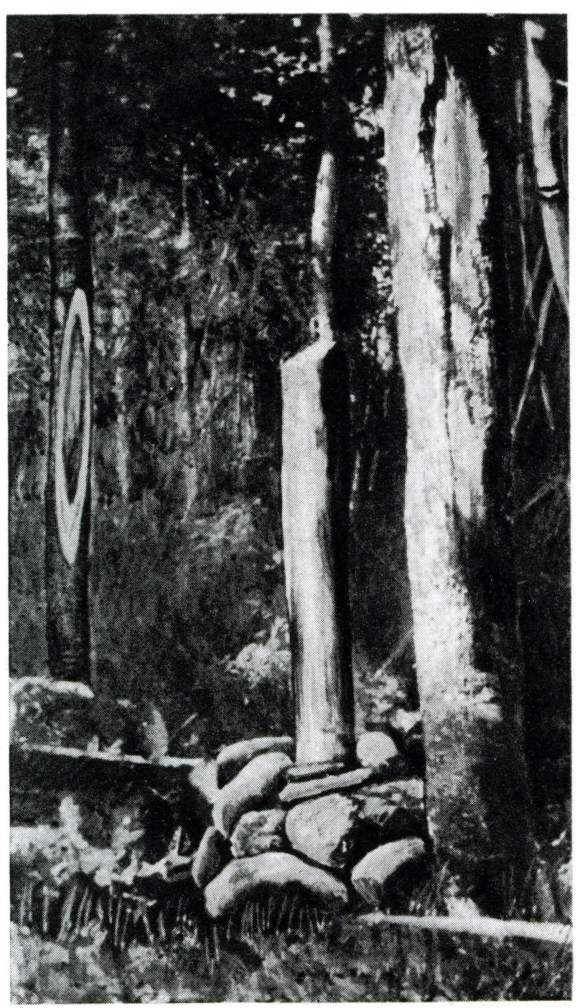

Corner post. not be deemed sufficient. Granting that such knowledge is correct it loses much of its value by not being always accessible to the manager himself, as is possible only when records and reports are on paper. One of the great weaknesses of the older estimators and woodsmen is their lack of ability to put their ideas on paper, so that the information contained therein will be available to other minds than their own.

$\mathrm{By}$ intelligible records and reports a knowledge of property is preserved. When management changes the new manager has already at hand the essential facts of his business, and can 


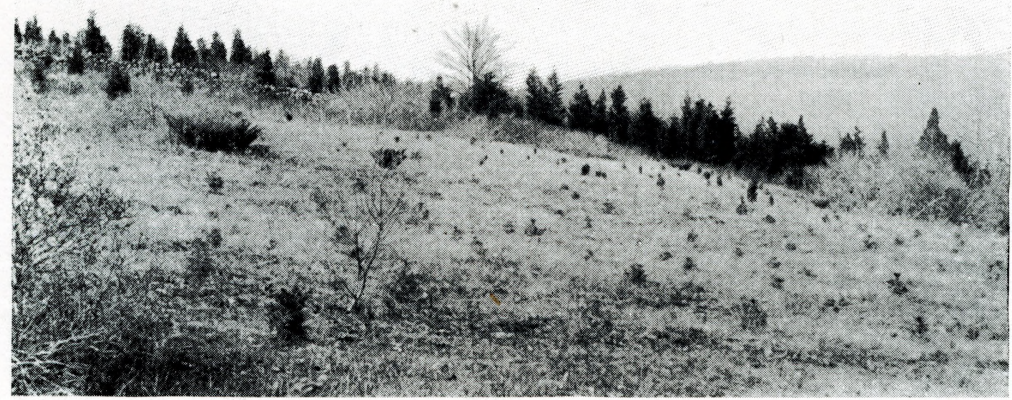

An experiment in white pine planting.

intelligently and economically carry on the policies best suited to the case.

If the manager has at his hand the requisite information regarding his tracts he can have a proper check on taxation, can treat intelligently and advantageously with prospective buyers, and can know what to count on in the way of timber estimates.

Having the boundaries properly delineated on the ground, by plain and correctly measured lines, will prevent trespass, allow better mapping control, and furnish needed data when considering exact area.

The efficient manager finds that there is an advantage in having the land cut up into as many subdivisions as is consistent with practical economy. Such subdivisions may be had by running regular spotted lines or by using natural features of division, such as heights of land. Square artificial divisions are generally recommended as being more definite and more evident on the ground to the logger. In making logging permits territory can be granted by watersheds within these divisions if desired. Subdivisions allow control of cutting, prevent waste in left timber, make inspection easier, and provide a basis for more intensive operations. Estimates are concentrated to easily checked quantities, and the employment of finer methods of mapping and selling are also made possible.

Detailed estimates of timber on each subdivision, and definite informatory reports as to handling will also prove invaluable to the 
manager. With these he can avoid over-valuation for taxation, can buy or sell with correct bargaining, and can place his logging contracts in the right locality and under right restrictions. He can also avoid leaving over-mature or diseased timber to become total losses. At every point increased knowledge adds to the profit and increases the efficiency of operations. There is never a premium on not knowing the exact conditions with which one has to deal.

Cost of forestry service

The cost of obtaining definite knowledge, based on adequate field work, varies in price from 4 cents to 20 cents per acre, according to the fineness of the work, number of subdivisions, speed in carrying out contracts, accessibility of tract, size of area, character of topography, character of timber, etc. This means from $1 / 2 \%$ to $3 \%$ of the value of ordinary woodland. Considering that the work once done will furnish accurate information for a lifetime it will be seen that the cost is comparatively small.

Forest

As a record of this work the manager or owner will have maps before him maps of his property, showing boundary lines and

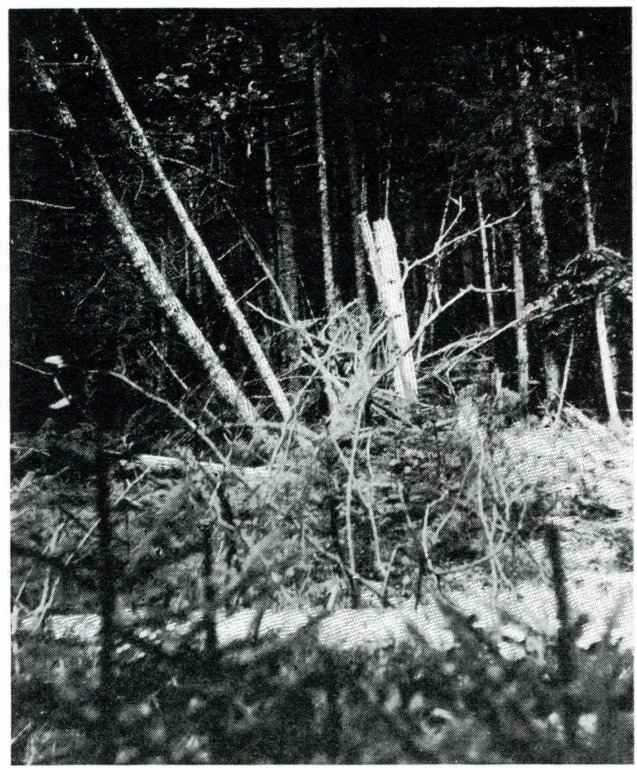

Have you slow-growing, shallow-rooted areas like this, which should not be thinned but cut clean? interior division lines, lakes, important streams, roads, burnt areas, bogs, and clearings, with camps, dams and other definite features accurately delineated; barometric contour lines at the necessary interval to give topography; colored and described growth types. At a glance the manager can see his whole territory far better than by a casual examination in the field of the property itself. 


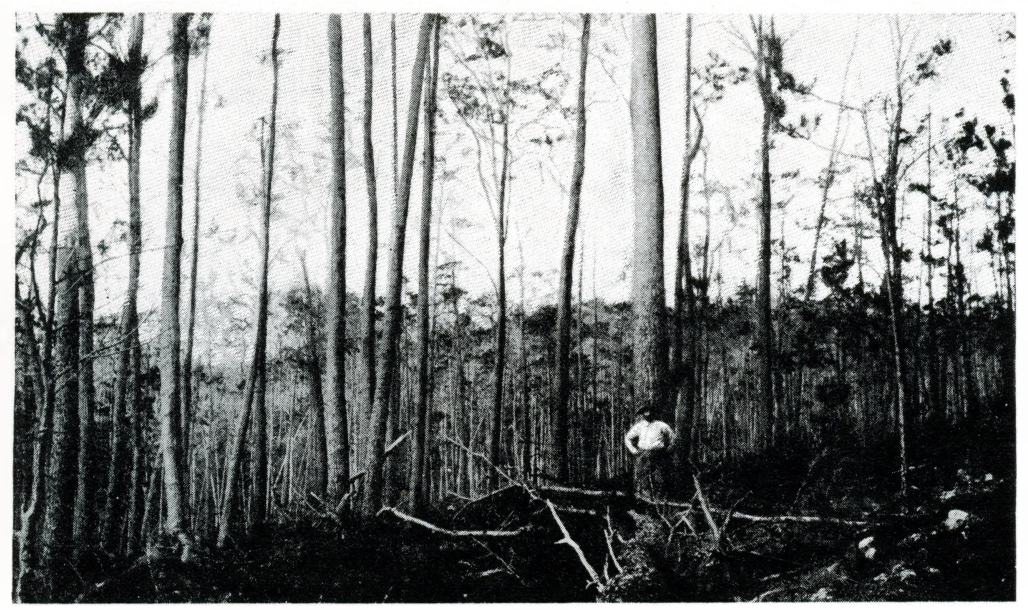

A Southern forest. One of our men estimated the timber on this tract.

These plans and other records may be kept up-to-date, with little yearly expense, additions of information being made by the regular field force of the concern, so that the initial expense of preparation is the only one necessary to consider. In this way the manager is able at any time to furnish himself or his directors with a birdseye view of the holdings and operations, and is able to look for years in advance on the location and result of cuttings. Directors are able intelligently to apprehend what is being done, and the manager intelligently to explain it.

Besides making surveys, estimates of timber, working plans, yield predictions and plantings, our services may be obtained for inspection of logging operations, planning of fire patrol systems, oversight and planning of logging railroad construction, and estimates of water power. Estates will also be managed for those who have not the desire nor the opportunity to act as their own agents.

If the regulations of the land owner or the recommendations of the forester are to amount to anything logging operations must be inspected. This work should be carried out at first by trained practical men, who will know what should be done, and compel it. A profitable system is to have a technical forester introduce systematic methods of procedure, and arrange the work so it can be carried on by cheaper men.

Necessary inspections 
Protection against fire

Will it pay?
Fire is the great natural enemy of the forest, and the best insurance against it is the protection offered by patrolling or by establishment of fire stations. We plan this work, laying out necessary lines of communication, such as telephones, roads, or lines of protection, and overseeing their construction.

We are also prepared to oversee the building of logging railways, making the surveys, and estimating the cost, making sure that the right of way becomes as much as possible a source of safety from fire rather than one of danger.

Many tracts of woodland depend for their value on the presence of water power adequate to carry on a mill. We will give estimates of this power, and location for mills at proper points. We do not, however, construct the mills, but leave that to the engineer.

The question of applying or not applying scientific forestry methods resolves itself into the question, "Will it pay?" The statement of cost per acre has been made. Now consider the cost per thousand feet board measure in ordinary lands. It will cost on an average about two cents per thousand to obtain definite, concise and permanent knowledge of the conditions underlying the operations. Stated this way the question answers itself. Few people could or would bring forth an argument to prove that definite knowledge is not worth that amount. The only remaining question is whether an owner or manager is sufficiently profit-loving to avail himself of knowledge which will prove of value far beyond the cost. 


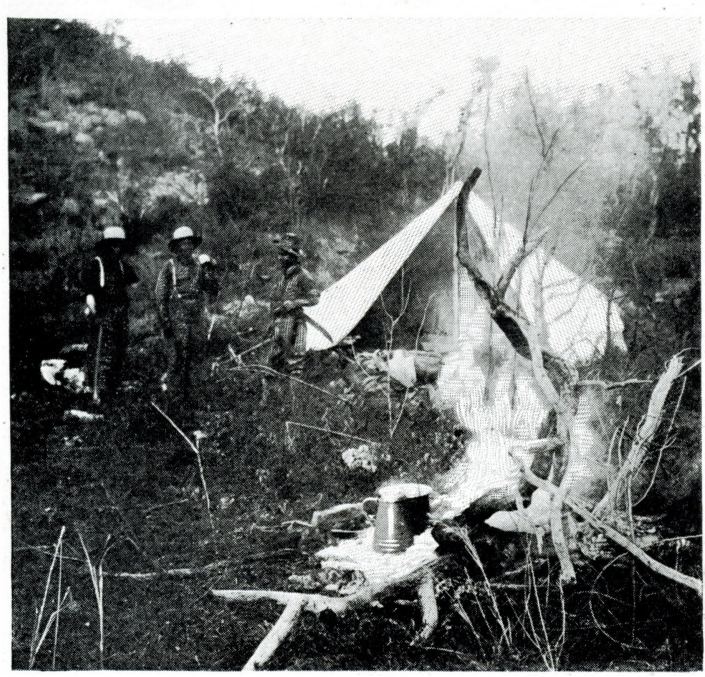

The end.

APPLETON \& SEWALL COMPANY, INC. FORESTERS AND SURVEYORS 156 FIFTH AVENUE, NEW YORK

INVITE CORRESPONDENCE FROM LAND OWNERS AND MANAGERS OF FOREST PROPERTIES 
GEORGE BATTEN COMPANY ADVERTISING

NEW YORK 


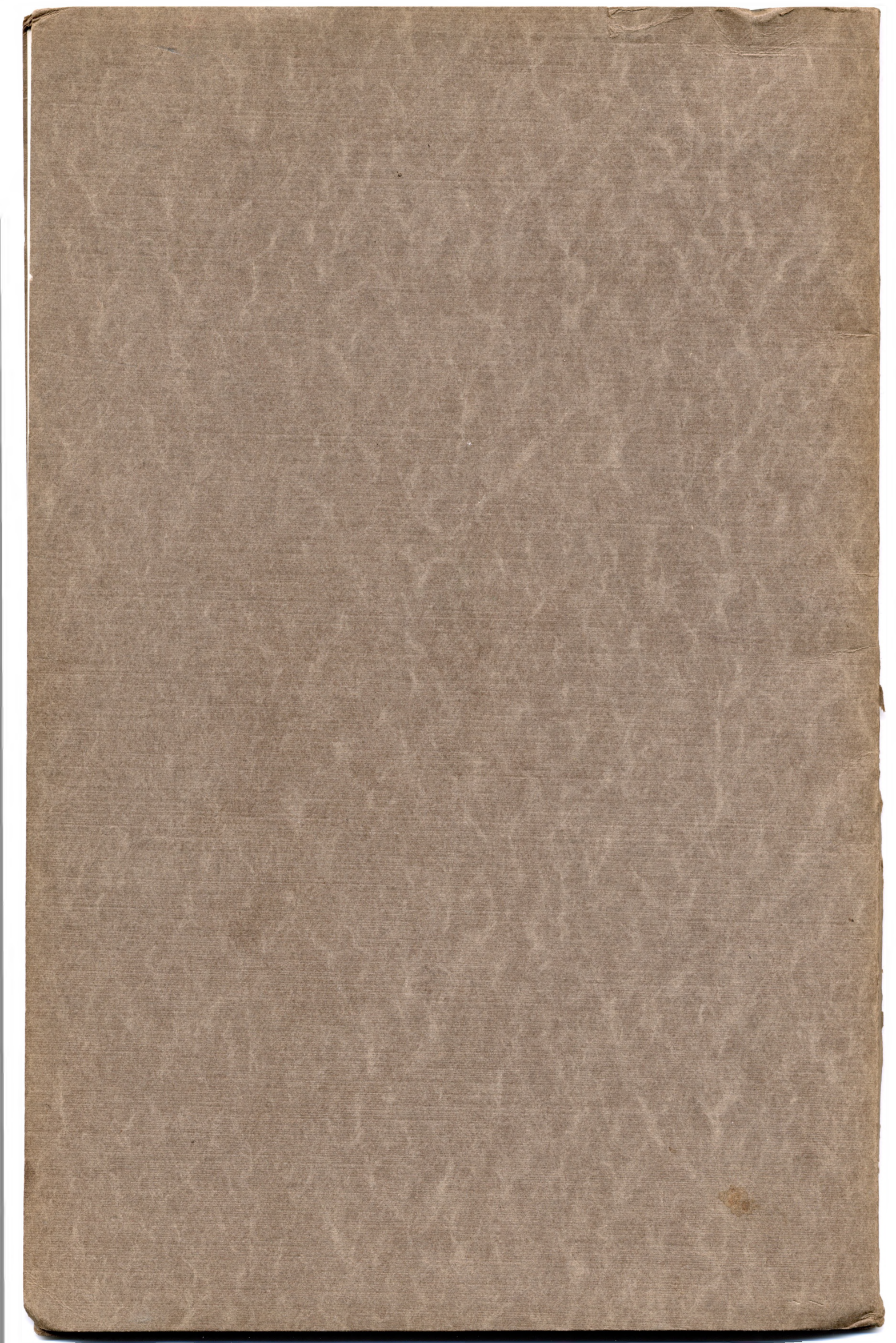

